\title{
Value of DNA image cytometry in the prediction of malignant change in Barrett's oesophagus
}

\author{
P D JAMES AND M ATKINSON \\ From the Department of Histopathology and Surgery, University Hospital, Queens Medical Centre, \\ Nottingham
}

SUMMARY DNA image cytometry was performed on Feulgen stained sections from 91 biopsies obtained during prospective endoscopic surveillance of 55 patients with Barrett's oesophagus. Aneuploid cells were detected in specimens from six of these patients. Four subsequently developed dysplasia and adenocarcinoma but, in the other two, biopsies had been reported as showing specialised epithelium only, with no apparent dysplasia and no evidence of malignancy on clinical follow up to date. In two of the four patients who subsequently developed carcinoma, aneuploid cells were only found in biopsies showing overt dysplasia or carcinoma but in the two other patients aneuploid cells were present in biopsies taken early in the clinical course before any dysplasia had been identified on the original reports. The presence of aneuploid cells on cytometry of these 'benign' biopsies allowed us, on histological review, to identify areas of atypia which were interpreted as mild dysplasia. In this series aneuploidy was always associated with-some morphological abnormality varying from mild dysplasia to frank carcinoma. Aneuploid cells were not shown in material from one patient who had an oesophagectomy for dysplasia or in biopsy material from four patients showing 'indefinite dysplasia'. DNA cytometry combines an objective assessment of epithelial atypia with the advantage of detecting rare cellular aneuploidy and the ability to correlate these events with morphology. It should assist in the more accurate diagnosis of dysplasia and prove useful in identifying those patients with Barrett's oesophagus who are at greater risk of subsequently developing malignancy.

The columnar epithelial lined oesophagus (CELO), described by Barrett in 1950, is the result of severe, prolonged gastro-oesophageal reflex ${ }^{2}$ and it carries a risk of developing adenocarcinoma. ${ }^{3}$ The magnitude of this risk differs widely in reported series ${ }^{4}$ and indeed some have been criticised for exaggerating the malignant potential. ${ }^{5}$ As yet there is no reliable marker to indicate which patient will develop adenocarcinoma and mucin histochemistry of Barrett's mucosa is not sufficiently discriminating to predict subsequent malignancy. ${ }^{467}$ At present dysplasia appears to be the only reliable indicator ${ }^{48}$ but the demonstration of aneuploidy by flow cytometry may be helpful in some cases. ${ }^{710}$

The present study attempts to assess microdensitometric DNA quantification as an indicator for detecting developing malignancy in patients with CELO.

Address for correspondence: Dr P D James, Dept of Histopathology, University Hospital, Queen's Medical Centre, Nottingham NG7 2UH.

Accepted for publication 7 November 1988.
This technique uses a computerised image analysis system which converts the size and staining intensity of nuclei in Feulgen stained sections into a DNA value for the cells measured. In contrast with flow cytometry, the measurements are made under direct visualisation which allows a correlation between the areas showing cellular aneuploidy and the morphology in adjacent conventionally stained sections. Flow cytometry will only identify a significant population of abnormal cells whereas cytometry will identify a single abnormal cell. The presence of aneuploid cells was taken to indicate malignancy or a malignant potential and was related to the known outcome in all cases.

\section{Methods}

PATIENTS

From 1977 all patients with a diagnosis of Barrett's oesophagus were entered into a programme of 
endoscopic surveillance with random biopsy. Those in whom carcinoma was present at first examination were excluded from the study. The diagnosis was made when the columnar mucosa extended circumferently up the oesophagus for $5 \mathrm{~cm}$ or more from the oesophagogastric junction which was defined endoscopically. At each examination the level of the squamocolumnar junction was measured from the incisor teeth and biopsies were taken randomly from the full extent of the columnar lined oesophagus. Latterly four quadrantic biopsies were taken at longitudinal intervals of $2-3 \mathrm{~cm}$. The clinical features, histology, and mucin histochemistry of the first 56 patients have been published. ${ }^{4}$

Adequate biopsy material was obtained from 55 patients and to date 194 biopsies were available for study. Biopsies were fixed in neutral buffered formalin, routinely processed to paraffin and stained with haematoxylin and eosin. Mucosubstances were demonstrated using alcian blue $\mathrm{pH} 2.5 /$ periodic acid schiff and high iron diamine-alcian blue $\mathrm{pH} 2.5$ stains. Each biopsy was examined for the histoloical type of epithelium present, ${ }^{11}$ the presence and type of intestinal metaplasia, ${ }^{12}$ and for dysplasia or carcinoma.

A system for grading dysplasia in inflammatory bowel disease has been proposed $d^{13}$ which has been applied to Barrett's oesophagus. ${ }^{514} 15$ The nomenclature used in this classification is shown in Table 1. Dysplasia is defined as an unequivocal neoplastic alteration in the columnar mucosa which is distinguishable from reactive or regenerative abnormalities. ${ }^{13}$ When a definite distinction is not possible, the changes are categorised as indefinite for dysplasia'.

DNA analysis was performed on at least one biopsy from each patient, the most recent biopsy containing adequate amounts of columnar epithelium was selected. In some unselected cases DNA analysis was performed on two or more biopsies. All biopsies showing any degree of cellular atypia and all biopsies from patients who subsequently developed malignant disease were studied. Five micron sections were cut, hydrolysed $\left(5 \mathrm{~N}\right.$ hydrochloric acid at $23^{\circ} \mathrm{C}$ for 50 minutes) and then stained with Schiff's reagent according to the Feulgen method. ${ }^{16}$

Table 1 Classification of dysplasia in Barrett's oesophagus

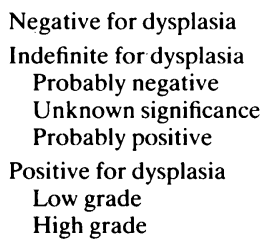

DNA IMAGE CYTOMETRY

Determinations of nuclear DNA were performed using the Leitz Miamed DNA system which has been developed from the Leitz Texture Analysis system. ${ }^{17}$ Slides were visualised by a Leitz. Ergolux Orthoplan microscope which had fully automated functions controlled by a microcomputer with television image analysis system. At least two levelled sections from each biopsy were examined.

The diploid standard (2c) of each biopsy was produced by counting at least 20 lymphocytes or as many as required to produce a standard error of less than $3 \%$ (coefficient of variation $<12$ in all cases), a correction factor of 1.19 was used between the DNA values of lymphocytes and epithelial cells. ${ }^{1 \times}$ The DNA content of at least 50 epithelial cells per biopsy was determined, nuclei were selected preferentially if they appeared morphologically large or atypical. Nuclei could be measured individually using grey level thresholding and touching or tightly packed nuclei could be separated and measured by outlining the nuclei with the aid of a rollerball 'mouse'.

Ancuploid cells were identified where the DNA content exceeded $5 \mathrm{c}$ and abnormal measurements

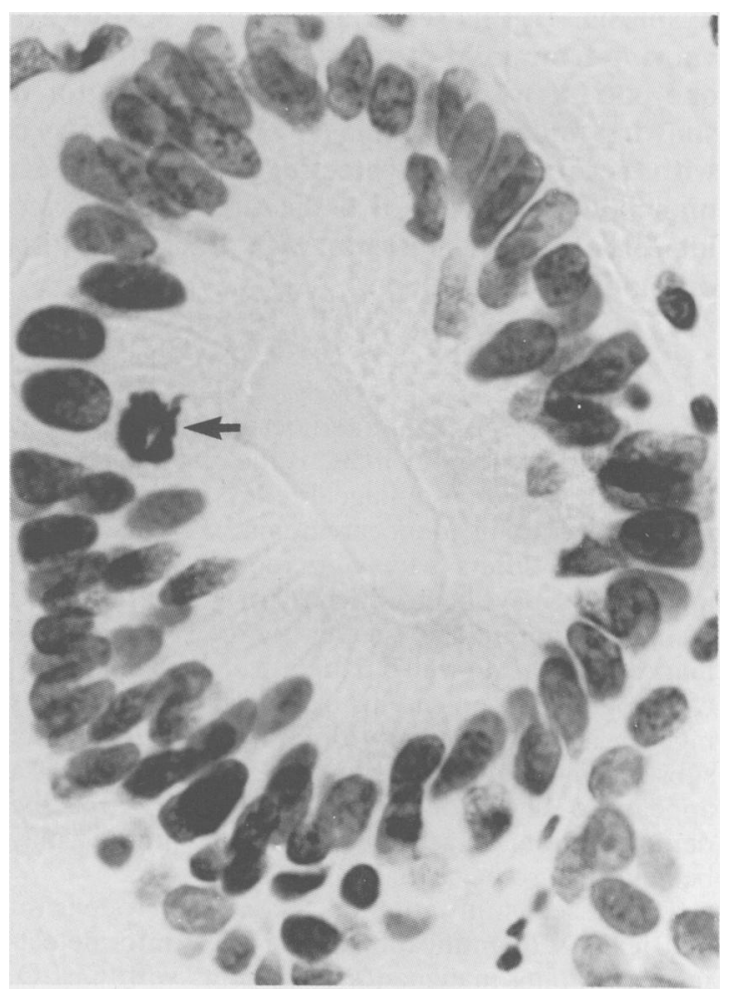

Fig. 1 Aneuploid mitosis (arrow) with DNA value $>5 \mathrm{c}$ in a mucosal biopsy originally reported as 'histologically' benign. Feulgen stain. 


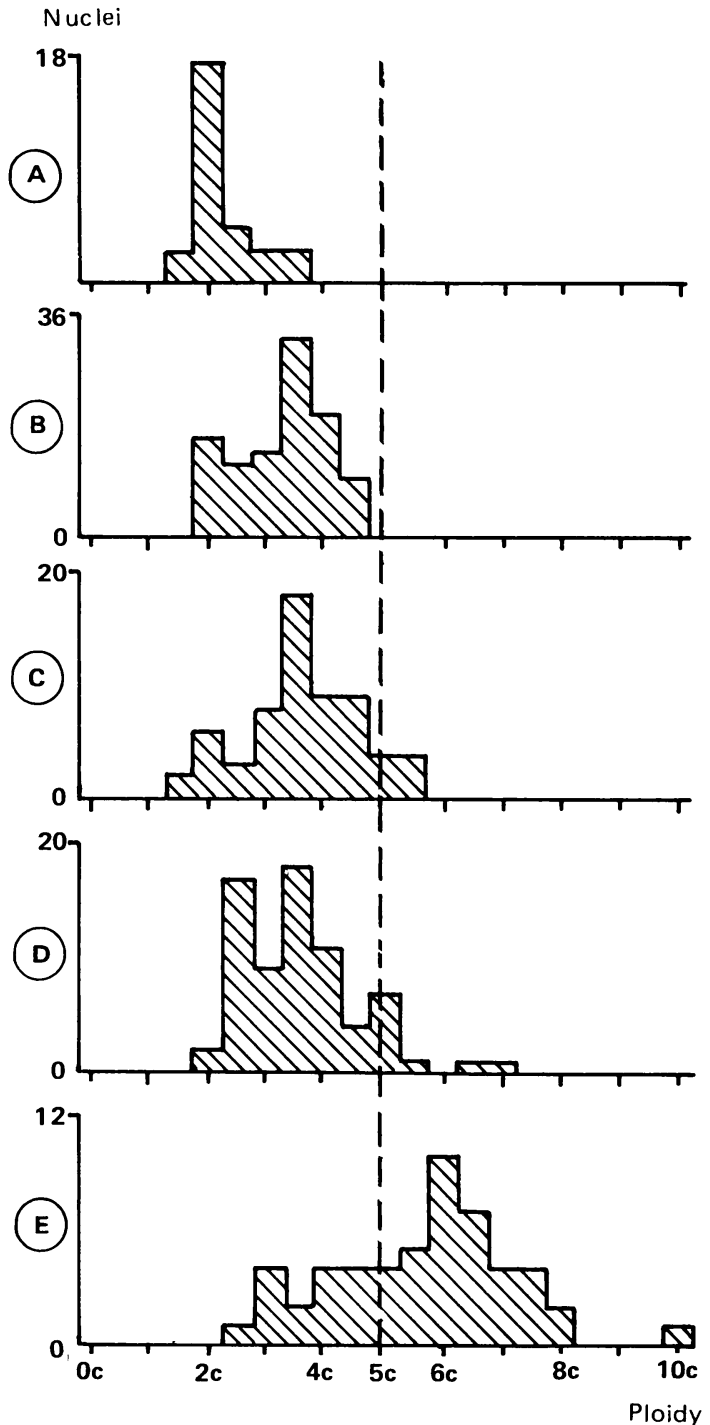

Fig. 2 Histograms of the DNA content of epithelial cells in the CELO. Normal DNA distribution with (a) diploid peak and $(b)$ diploid and tetraploid peaks. Abnormal DNA

distribution, (c) one of two patients in whom biopsy material was originally reported as benign, (d) patient with dysplasia, and (e) with adenocarcinoma, all showing aneuploid (DNA>5 c) cells present.

were repeated at least three times to ensure their accuracy. A biopsy was deemed abnormal only when three separate aneuploid cells were identified and where this observation was confirmed on a further section from the same biopsy. Overlapping nuclei, a common feature of dysplastic epithelium, precluded measurements in some areas. Mitotic figures, which

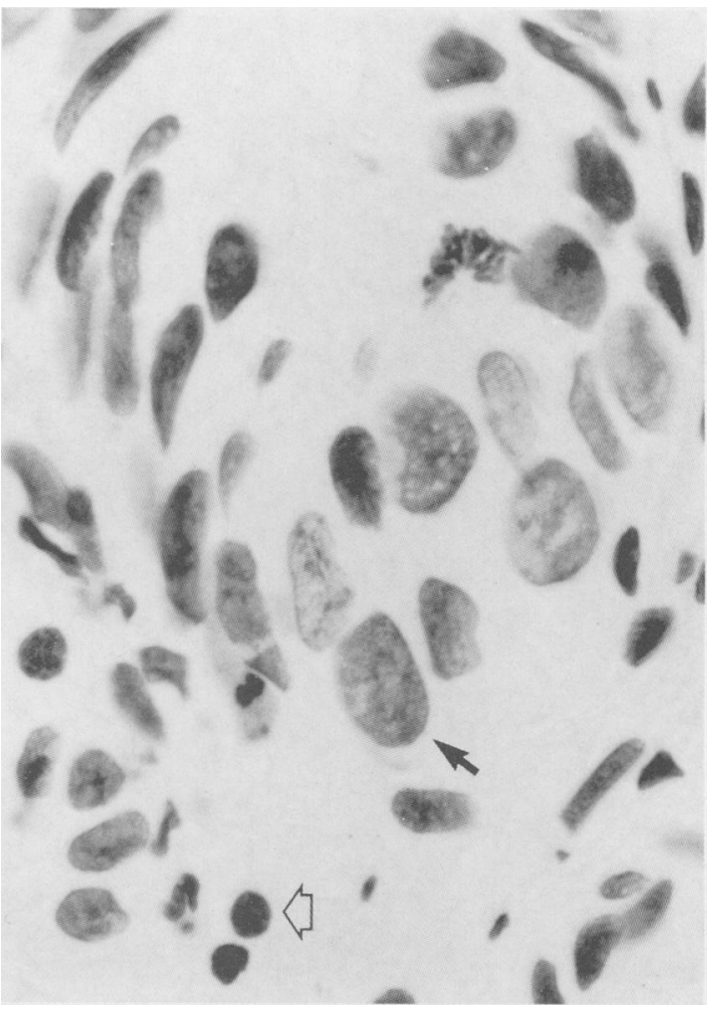

Fig. 3 Aneuploid cell (black arrow) in a biopsy from a patient, originally reported as benign. Lymphocyte nucleus (white arrow) for size comparison. Feulgen stain.

were often present, could be measured as these were situated towards the luminal aspect of the columnar epithelium away from the epithelial nuclei (Fig. 1). A DNA histogram was produced for each biopsy.

\section{Results}

Sixty one biopsies of histologically benign columnar mucosa examined from 48 patients (one biopsy 38 patients, two biopsies seven patients, three biopsies three patients) showed normal DNA profiles (Figs 2 a and $b$ ). These results included two biopsies each from four patients in which 'indefinite dysplasia probably negative' had been reported. In two patients with previously reported benign mucosa, the most recent of two biopsies examined showed aneuploid cells (Figs $2 \mathrm{c}, 3$ ). Review of these biopsies showed foci of mild dysplasia corresponding to the areas in which aneuploid cells were detected (Fig. 4).

Four patients developed adenocarcinoma during the study period and aneuploid cells were present in all the biopsies which were originally reported as 


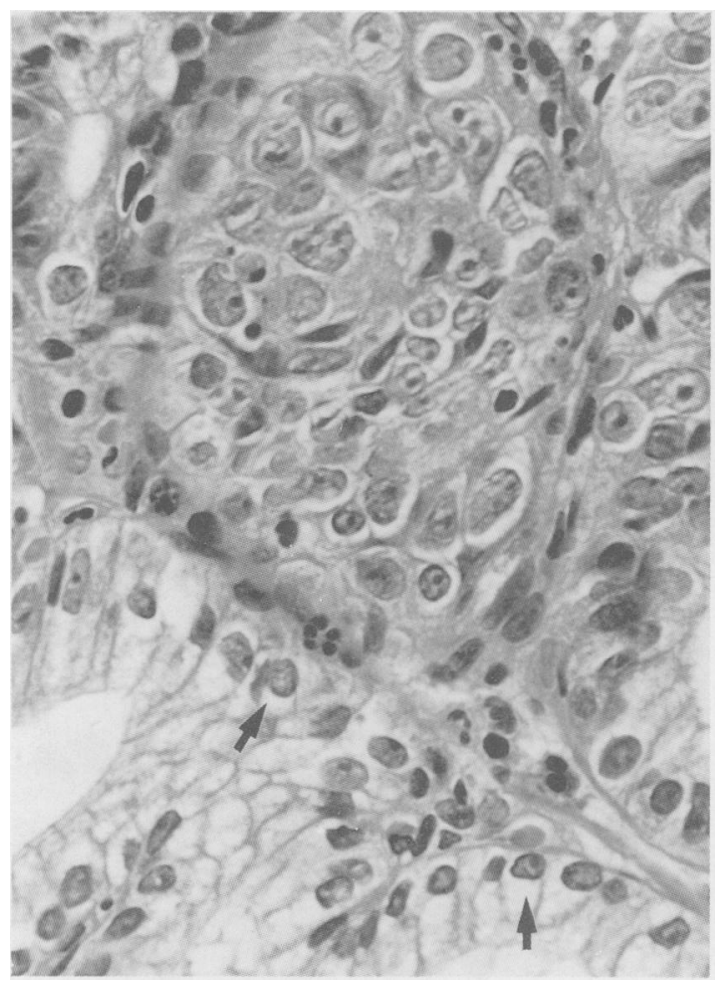

Fig. 4 Adjacent section to that shown in Fig. 3. Large, pleomorphic epithelial cells with multiple nucleoli are present. Nuclei in adjacent pyloric type glands (arrows) for comparison. Haematoxylin and eosin.

showing dysplasia or carcinoma (Figs $2 \mathrm{~d}$, e). In two of these patients aneuploid cells were present in the biopsies taken at presentation and no dysplasia had been identified in the original biopsy reports. Review of the biopsy material in the light of the cytometry findings, however, showed areas of mild dysplasia which had been previously overlooked or dismissed. In both these patients the presence of aneuploid cells persisted in subsequent biopsies which had been reported as showing either 'indefinite dysplasia probably negative', 'indefinite dysplasia probably positive', overt dysplasia or adenocarcinoma. In the two other patients with adenocarcinoma no aneuploid cells were detected in the predysplastic biopsies. Table 2 shows details of biopsy interval, histology, original and review grade of dysplasia and DNA profile in the four cases of malignant CELO.

A further patient had an oesophagectomy for severe dysplasia but on review of the biopsy material the changes were interpreted as 'indefinite dysplasia probably negative'. DNA analysis showed no
Table 2 Biopsy interval, histology, original, and review grade of dysplasia and DNA profile of four cases of malignant CELO

\begin{tabular}{|c|c|c|c|c|c|}
\hline & \multirow[b]{2}{*}{ Time* } & \multirow[b]{2}{*}{ Histology ${ }^{\dagger}$} & \multicolumn{2}{|c|}{ Dysplasia } & \multirow[b]{2}{*}{ DNA } \\
\hline & & & Original & Revie'w & \\
\hline \multirow[t]{8}{*}{ Case 1} & () & $\mathrm{J}+\mathrm{S}$ & Neg & LGD & Aneuploid \\
\hline & 17 & $\mathrm{~J}+\mathrm{S}$ & IPN & LGD & Aneuploid \\
\hline & 44 & $\mathrm{~J}+\mathrm{S}$ & IPN & LGD & Aneuploid \\
\hline & 60 & $\mathrm{~J}+\mathrm{S}$ & HGD & HGD & Aneuploid \\
\hline & 66 & $\mathrm{~J}+\mathrm{S}$ & HGD & HGD & Ancuploid \\
\hline & 69 & - & IM Ca & IM Ca & Aneuploid \\
\hline & 72 & - & IMCa & IMCa & Aneuploid \\
\hline & 78 & Oesophagectomy & IM Ca & IM Ca & Aneuploid \\
\hline \multirow[t]{8}{*}{ Case 2} & ) & $\mathbf{J}$ & Neg & LGD & Aneuploid \\
\hline & 5 & $\mathrm{~J}+\mathrm{S}$ & Neg & Neg & Normal \\
\hline & 23 & $\mathrm{~J}+\mathrm{S}$ & IPN & LGD & Aneuploid \\
\hline & 42 & $\mathbf{J}$ & LGD & LGD & Aneuploid \\
\hline & 48 & $\mathrm{~J}+\mathrm{S}$ & HGD & HGD & Aneuploid \\
\hline & 56 & - & IM Ca & IM Ca & Aneuploid \\
\hline & 56 & - & IMCa & IMCa & Ancuploid \\
\hline & 57 & Oesophagectomy & IV Ca & IV Ca & - \\
\hline \multirow[t]{7}{*}{ Case $3 \$$} & 0 & $\mathbf{J}+\mathbf{S}$ & Neg & Neg & Normal \\
\hline & 5 & $\mathrm{~J}+\mathrm{S}$ & Neg & Neg & Normal \\
\hline & 14 & $\mathrm{~J}+\mathrm{S}$ & $\mathrm{Neg}$ & Neg & Normal \\
\hline & 21 & $\mathrm{~J}+\mathrm{S}$ & Neg & Neg & Normal \\
\hline & 29 & $\mathrm{~J}+\mathrm{S}$ & LGD & LGD & Aneuploid \\
\hline & 30 & $\mathrm{~J}+\mathrm{S}$ & HGD & HGD & Aneuploid \\
\hline & 40 & - & IM Ca & IM Ca & Aneuploid \\
\hline \multirow{4}{*}{ Case 4} & 0 & Sq & - & - & - \\
\hline & 2 & $J+S$ & Neg & Neg & Normal \\
\hline & 11 & - & IMCa & $\mathrm{IMCa}$ & Aneuploid \\
\hline & 12 & Oesophagectomy & IVCa & IV Ca & Aneuploid \\
\hline
\end{tabular}

*Biopsy interval in months from presentation; $+\mathrm{Sq}=$ squamous: $\mathrm{J}=$ junctional: $\mathrm{J}+\mathrm{S}=$ junctional and specialised: $t$ neg=negative for dysplasia: IPN =indefinite for dysplasia, probably negative:

IPP =indefinite for dysplasia, probably positive: $\mathrm{LGD}=10 \mathrm{w}$ grade dysplasia: $\mathrm{HGD}=$ high grade dysplasia: $\mathrm{IM} \mathrm{Ca}=$ intramucosal carcinoma: IV $\mathrm{Ca}=$ invasive carcinoma: \$Patient unfit for surgical resection.

aneuploid cells in three biopsies examined or in the oesophagectomy specimen.

\section{Discussion}

The columnar epithelial lined oesophagus (CELO) is clearly a precancerous condition but reports of the magnitude of this risk differ widely and prevalence studies, which include patients presenting with adenocarcinoma, tend to exaggerate the risk of malignancy. ${ }^{14}$ The incidence among the 56 patients from this unit was one per 54.4 patient-years follow up which contrasts with two studies from $\mathrm{New}$ Zealand in which no malignant changes occurred. ${ }^{112} 21$ Cameron, ${ }^{21}$ however, reported two carcinomas in 102 patients giving an incidence of one case per 441 patient-years and Spechler ${ }^{22}$ reported two cases of carcinoma in a series of 105 patients, a rate of one per 175 patient-years. A further series ${ }^{23}$ reported onc 
case per 166 patient-years. Endoscopic surveillance is advisable in all patients with CELO but changes in symptomatology or gross endoscopic appearance are often absent even after adenocarcinoma has developed. ${ }^{4}$ Biopsy is therefore essential for the early diagnosis of malignancy.

The mucin histochemistry of Barrett's mucosa has been studied ${ }^{6-8426}$ and these reports show that incomplete intestinal metaplasia and sulphomucin secretion are common features. A recent study ${ }^{4}$ showed intestinal metaplasia and sulphomucin secretion in $64 \%$ and $58 \%$ of biopsies respectively, both being present in at least one biopsy from $78 \%$ of the patients studied. Sulphomucin secretion in specialised mucosa is not a sufficiently sensitive marker to predict those at risk of developing adenocarcinoma. ${ }^{467}$ All our patients, however, who subsequently developed malignant change showed specialised epithelium and sulphomucin secretion in earlier biopsies.

At present dysplasia appears to be the only reliable marker for adenocarcinoma ${ }^{89}$ and a long latent period, varying from many months to several years, may occur between its onset and the development of adenocarcinoma. ${ }^{48}$ There are, however, wide interobserver variations in the assessment of dysplasia ${ }^{27}$ therefore, at present, it lacks objectivity and the malignant potential of early changes may be missed.

The advent of DNA analysis using flow cytometry has provided an objectivity which had hitherto been lacking in the assessment of morphological abnormalities in the gastrointestinal tract. Reid ${ }^{9}$ found aneuploid cells in 10 patients with Barrett's oesophagus; nine of these had dysplasia, carcinoma or both but one patient had only specialised metaplastic epithelium. McKinley ${ }^{10}$ found aneuploidy in $79 \%$ of oesophageal malignancy and in seven patients with CELO, two of whom had dysplasia. Aneuploidy, however, is not present in all gastrointestinal tumours subjected to flow cytometry ${ }^{102}$ and aneuploid cells were reported to be present in only two of four cases of dysplastic Barrett's. ${ }^{9}$ This may be because these cells form a minority population, too small to be detected by flow cytometry and this has raised doubts about the value of DNA analysis in Barrett's oesophagus. ${ }^{29}$

The present study utilises DNA image cytometry ${ }^{18}$ which has been shown to correlate well with the results obtained by flow cytometry. ${ }^{30}$ This technique has been shown to be of value in dysplasia in longstanding ulcerative colitis ${ }^{31}$ and gastric adenomas. ${ }^{32}$ The advantages of image cytometry over other methods are the ability to detect a single 'rare event' aneuploid cell ${ }^{33}$ and the direct visualisation of abnormal cells which can be related to morphological changes on the Feulgen or adjacent haematoxylin and eosin stained sections. This latter facility can be used to train morphologists to detect and improve evaluation of small or subtle areas of atypia which may otherwise be overlooked or dismissed as insignificant. This is shown in the present study where the presence of aneuploid cells in apparently normal biopsies caused us to review the histological material and reassess the degree of dysplasia present (see Table 2). When more material has been studied, it may be necessary to reevaluate the criteria for diagnosing dysplasia in the light of the small areas of cellular atypia identified by cytometry.

This technique is time consuming and labour intensive, one to two hours were needed to adequately examine some of the larger biopsies and there were advantages in having a trained morphologist perform the analyses. The development of small 'in microscope' systems for DNA quantitation, however, could make this a routine evaluation. Some degree of caution was necessary in interpretation as abnormal measurements due to overlapping nuclei could not be excluded on every isolated measurement. Therefore a biopsy was deemed abnormal only when three separate aneuploid cells were identified and where this observation was confirmed on a further section from the same biopsy. In some biopsies overlapping nuclei within dysplastic foci precluded adequate cell estimations although mitoses, when present, could be measured. These constraints would tend to underestimate the number of aneuploid cells present.

A normal DNA profile was found in all our cases with a benign clinical course, these included eight biopsies from four patients showing indefinite dysplasia probably negative'. In all four patients who developed carcinoma, aneuploid cells were present in the biopsies which showed dysplasia or carcinoma. On the basis of this small series DNA analysis would seem to provide an excellent discriminator between benign and malignant biopsies as well as assisting in the diagnosis of atypia. One patient had an oesophagectomy for severe dysplasia which, on review was downgraded to 'indefinite dysplasia probably negative' and no aneuploid cells were detected in the three biopsies examined, nor in samples taken from the oesophagectomy specimen. In two patients with biopsies which were originally reported as showing apparently benign columnar epithelium, aneuploid cells were detected in the most recent biopsies but there is no further follow up to date. Review of the biopsy material in these two cases showed small foci of mild dysplasia which had been previously overlooked. Review of the two cases of malignant Barrett's, in which aneuploid cells had been found in biopsies originally reported as 'non dysplastic', also showed foci of mild dysplasia. This technique, 
because of the detailed observation required, provides sensitivity and objectivity to simple morphology.

At present it is not possible to make an adequate evaluation of DNA analysis as an adjunct to biopsy in the endoscopic surveillance of Barrett's oesophagus. Our study, which is the first to report the use of DNA image cytometry in Barrett's oesophagus, suggests that this technique is useful in the positive identification of dysplasia and the absence of aneuploid cells is reassuring evidence that areas of atypia are 'negative for dysplasia'. The finding of aneuploid cells in apparently normal biopsies should alert the morphologist to the possibility of small areas of dysplasia which have been overlooked. In two of the four patients in our series who developed adenocarcinoma no aneuploid cells were seen before the onset of dysplasia. This may in part be because of biopsy sampling but further work is required to evaluate DNA analysis as a screening procedure.

We wish to thank Ms Mandy Orchard for typing the manuscript, Mr Bill Brackenbury for photomicrography, Mr Trevor Grey for technical assistance, $\mathrm{Dr}$ Jim Lowe and Professor David Turner for reviewing the manuscript.

\section{References}

1 Barrett NR. Chronic peptic ulcer of the oesophagus and 'oesophagitis'. Br J Surg 1950; 38: 175-82.

2 Winters C, Spurling TJ, Chobanian SJ, et al. Barrett's esophagus. A prevalent, occult complication of gastroesophageal reflux disease. Gastroenterology 1987; 92: 118-24.

3 Naef AP, Savary M, Ozzello L. Columnar-lined lower esophagus: An acquired lesion with malignant predisposition. Report on 140 cases of Barrett's esophagus with 12 adenocarcinomas. J Thorac Cardiovasc Surg 1975; 70: 826-34.

4 Robertson CS, Mayberry JF, Nicholson DA, James PD, Atkinson M. Value of endoscopic surveillance in the detection of neoplastic change in Barrett's oesophagus. Br J Surg 1988; 75: 760-3.

5 Spechler SJ, Goyal RK. Barrett's esophagus. N Engl J Med 1986; 315: 362-71.

6 Rothery GA, Patterson JE, Stoddard CJ, Day DW. Histological and histochemical changes in the columnar lined (Barrett's) oesophagus. Gut 1986; 27: 1062-8.

7 Haggit RC, Reid BJ, Rabinovitch PS, Rubin CE. Barrett's esophagus. Correlation between mucin histochemistry, flow cytometry, and histologic diagnosis for predicting increased cancer risk. Am J Pathol 1988; 131: 53-61.

8 Lee RG. Dysplasia in Barrett's esophagus. A clinicopathologic study of six patients. Am J Surg Pathol 1985; 9: $845-52$.
9 Reid BJ, Haggitt RC, Rubin CE, Rabinovitch PS. Barrett's esophagus. Correlation between flow cytometry and histology in detection of patients at risk for adenocarcinoma. Gastroenterology 1987; 93: 1-11.

10 McKinley MJ, Budman DR, Grueneberg D, Bronzo RL, Weissman GS, Kahn E. DNA content in Barrett's esophagus and esophageal malignancy. Am J Gastroenterol 1987; 82: 1012-5.

11 Paull A, Trier JS, Dalton MD, Camp RC, Loeb P, Goyal RK. The histologic spectrum of Barrett's esophagus. N Engl J Med 1976; 295: 476-80.

12 Filipe MI, Jass JR. Intestinal metaplasia subtypes and cancer risk. In: Filipe MI, Jass JR, eds. Gastric carcinoma. Edinburgh: Churchill Livingstone, 1986.

13 Riddell RH, Goldman H, Ransohoff DF, et al. Dysplasia in inflammatory bowel disease: standardized classification with provisional clinical applications. Hum Pathol 1983; 14: 931-68.

14 Skinner DB, Walther BC, Riddell RH, Schmidt H, Iascone C, DeMeester TR. Barrett's esophagus. Comparison of benign and malignant cases. Ann Surg 1983; 198: 554-65.

15 Hamilton SR, Smith RL. The relationship between columnar epithelial dysplasia and invasive adenocarcinoma arising in Barrett's esophagus. Am J Clin Pathol 1987; 87: 301-12.

16 Mays RGW. The Feulgen hydrolysis profiles a metastatic lung tumour in lymph node and a primary breast carcinoma. Med Lab Sci 1987; 44: 307-11.

17 Leitz Instruments, Park Street, Luton LU1 3HP, England.

18 Bocking A, Adler CP, Common HH, Hilgarth M, Granzen B, Auffermann W. Algorithm for a DNAcytophotometric diagnosis and grading of malignancy. Anal Quant Cytol 1984; 6: 1-8.

19 Borrie J, Goldwater L. Columnar cell-lined oesophagus: assessment of etiology and treatment. A 22 year experience. J Thorac Cardiovasc Surg 1976; 71: 825-34.

20 Cooper BT, Barbezat GO. Barrett's oesophagus: a clinical study of 52 patients. $Q \mathrm{~J}$ Med 1987; 62: 97-108.

21 Cameron AJ, Ott BJ, Payne WS. The incidence of adenocarcinoma in columnar-lined (Barrett's) esophagus. $N$ Engl J Med 1985; 313: 857-9.

22 Spechler SJ, Robbins AH, Rubins HB, et al. Adenocarcinoma and Barrett's esophagus. An overrated risk? Gastroenterology 1984; 87: 927-33.

23 Achkar E, Carey W. The cost of suveillance for adenocarcinoma complicating Barrett's esophagus. Am J Gastroenterol 1988; 83: 291-4.

24 Jass JR. Mucin histochemistry of the columnar epithelium of the oesophagus: a retrospective study. J Clin Pathol 1981; 34: 866-70.

25 Sheahan DG, West AB. Sulfated mucosubstances in Barrett's (columnar cell) esophageal mucosa. Gastroenterology 1981; 80: 1282.

26 Peuchmaur M, Potet F, Goldfain D. Mucin histochemistry of the columnar epithelium of the oesophagus (Barrett's oesophagus): a prospective biopsy study. J Clin Pathol 1984; 37: 607-10.

27 Reid BJ, Haggitt RC, Rubin CE, et al. Criteria for dysplasia in Barrett's esophagus: a cooperative consensus study. Gastroenterology 1985; 88: 1552. 
28 Ballantyne KC, James PD, Robins RA, Baldwin RW, Hardcastle JD. Flow cytometric analysis of the DNA content of gastric cancer. Br J Cancer 1987; 56: 52-4.

29 Ahnen DJ. Flow cytometric analysis of deoxyribonucleic acid content in the gastrointestinal tract. Is aneuploidy more than a new ploy? Gastroenterology 1987; 93: 197-203.

30 Cornelisse CJ, Van Driel-Kulker AMJ. DNA image cytometry on machine-selected breast cancer cells and a comparison between flow cytometry and scanning cytophotometry. Cytometry 1985; 6: 471-7.

31 Cuvelier CA, Morson BC, Roels HJ. The DNA content in cancer and dysplasia in chronic ulcerative colitis. Histopathology 1987; 11: 927-39.

32 Rubio CA, Kato Y. DNA profiles in mitotic cells from gastric adenomas. Am J Pathol 1988; 130: 485-8.

33 Walle AJ, Niedermayer W. Aneuploidy as a marker of minimal residual disease in leukaemia. Cancer Detect Prev 1985; 8: 303-15. 